\title{
Flexibility in a changing arctic food web: Can rough-legged buzzards cope with changing small rodent communities?
}

\author{
Ivan A. Fufachev ${ }^{1}$ (D) | Dorothee Ehrich ${ }^{2}$ (D) | Natalia A. Sokolova ${ }^{1,3}$ (D) | \\ Vasiliy A. Sokolov ${ }^{4}$ (D) | Aleksandr A. Sokolov ${ }^{1,3}$ (D)
}

${ }^{1}$ Arctic Research Station of Institute of Plant and Animal Ecology, Ural Branch of Russian Academy of Sciences, Labytnangi, Russia

${ }^{2}$ Department of Arctic and Marine Biology, UiT - The Arctic University of Norway, Tromsø, Norway

${ }^{3}$ Arctic Research Center of Yamal-Nenets Autonomous District, Salekhard, Russia

${ }^{4}$ Institute of Plant and Animal Ecology, Ural Branch of Russian Academy of Sciences, Ekaterinburg, Russia

\section{Correspondence}

Dorothee Ehrich, Department of Arctic and Marine Biology, UiT - The Arctic University of Norway, 9037 Tromsø, Norway.

Email: dorothee.ehrich@uit.no

Funding information

Ural Division of the Russian Academy of Sciences, Grant/Award Number: 12-4-7-022-Arctic, 18-9-4-22-Arctic and 15-15-4-35; Fram Centre - High North Centre for Climate and the Environemnent, Grant/Award Number: 362259; Russian Foundation for Basic Research, Grant/Award Number: 16-44-890108, 18-54-15013 and 18-05-60261; Norges Forskningsråd, Grant/ Award Number: 176097/S30

\begin{abstract}
Indirect effects of climate change are often mediated by trophic interactions and consequences for individual species depend on how they are tied into the local food web. Here we show how the response of demographic rates of an arctic bird of prey to fluctuations in small rodent abundance changed when small rodent community composition and dynamics changed, possibly under the effect of climate warming. We observed the breeding biology of rough-legged buzzards (Buteo lagopus) at the Erkuta Tundra Monitoring Site in southern Yamal, low arctic Russia, for 19 years (1999-2017). At the same time, data on small rodent abundance were collected and information on buzzard diet was obtained from pellet dissection. The small rodent community experienced a shift from high-amplitude cycles to dampened fluctuations paralleled with a change in species composition toward less lemmings and more voles. Buzzards clearly preferred lemmings as prey. Breeding density of buzzards was positively related to small rodent abundance, but the shift in small rodent community lead to lower numbers relative to small rodent abundance. At the same time, after the change in small rodent community, the average number of fledglings was higher relative to small rodent abundance than earlier. These results suggest that the buzzard population adapted to a certain degree to the changes in the major resource, although at the same time density declined. The documented flexibility in the shortterm response of demographic rates to changes in structure and dynamics of key food web components make it difficult to predict how complex food webs will be transformed in a warmer Arctic. The degree of plasticity of functional responses is indeed likely to vary between species and between regions, depending also on the local food web context.
\end{abstract}

\section{KEYWORDS}

breeding success, diet selectivity, food web, indirect effects of climate change, lemming cycles, numerical response, rough-legged buzzard, trophic interactions

This is an open access article under the terms of the Creative Commons Attribution-NonCommercial License, which permits use, distribution and reproduction in any medium, provided the original work is properly cited and is not used for commercial purposes.

(c) 2019 The Authors. Global Change Biology published by John Wiley \& Sons Ltd 


\section{1 | INTRODUCTION}

The effects of climate change on ecosystems are often difficult to predict, because species are interlinked in complex interaction networks and changes in one species can have consequences for many others (Koltz, Classen, \& Wright, 2018; Schmidt et al., 2017). Indirect effects of climate-driven changes in species abundance or guild composition are often mediated by trophic interactions, and shifts in the relative abundance of species can lead to changes in interaction strength and food web dynamics (Martin, 2007; Mortensen, Schmidt, Høye, Damgaard, \& Forchhammer, 2016). Changes in food web structure resulting from climate change are more likely to be detrimental to specialist than to generalist species, because of their dependence on specific resources (Clavel, Julliard, \& Devictor, 2011). The ability of species to cope with climate-driven changes in food webs depends on the interplay between their dietary flexibility, the responses of demographic rates to changes in resource availability, and individual variation in these responses, which together will determine the potential of populations to adapt to new conditions.

Cycles of key herbivores are characteristic for many northern terrestrial food webs (Boonstra et al., 2016) and have become classical model systems to study predator-prey interactions (Gilg, Hanski, \& Sittler, 2003; Krebs, 2011). These cycles are susceptible to be disrupted by climate change leading to periods with dampened amplitudes lacking the typical peak abundance years (Cornulier et al., 2013; Ims, Henden, \& Killengreen, 2008). Thus, in some areas of the Arctic, the multiannual fluctuations of lemming populations (Lemmus or Dicrostonyx sp.) have faded out in the last decades, a change in a key ecosystem process which has been attributed to deteriorating snow conditions resulting from warmer, shorter, and more variable winters (Gilg, Sittler, \& Hanski, 2009; Ims, Yoccoz, \& Killengreen, 2011; Kausrud et al., 2008). Changes from cyclic to noncyclic small rodent dynamics have been described as regime shifts, because they have profound influences on the functioning of the ecosystems where they occur (Ims et al., 2008). The disappearance of regular lemming peaks can have catastrophic consequences for specialist predators like snowy owls (Bubo scandiaca) in eastern Greenland (Schmidt et al., 2012) or arctic foxes (Vulpes lagopus) in northern Scandinavia (Ims et al., 2017), whereas more flexible generalists are less affected. Millon et al. (2014) investigated the functional response of demographic rates of tawny owls (Strix aluco) to fluctuating vole abundances before and after a dampening of vole cycles and documented a drastic reduction in breeding probability with changed prey dynamics. However, to the best of our knowledge, possible changes in the responses of predator demographic rates to prey abundance resulting from changes in dynamics or species composition of the prey community have not been documented. Responses could change with a regime shift in small rodent dynamics if the predator's response at the population level is flexible, for example, because a population is composed of individuals with different individual adaptations. In order to understand the consequences of changes in the dynamics of key ecosystem components, it is important to investigate whether and how trophic interactions, which are characterized by the numerical and functional responses of consumers to their major resources, are modified by changed resource availability.

Here we study the breeding biology and diet of rough-legged buzzards (B. lagopus) in relation to changes in dynamics and species composition of a low arctic small rodent community. The small rodent population experienced a transition from a high amplitude state to low amplitude irregular fluctuations, and a stronger decrease in lemming populations led to a vole dominated community typical for subarctic areas (Ims \& Fuglei, 2005; Sokolova et al., 2014). The rough-legged buzzard (hereafter buzzard) is a moderate small rodent specialist (Hellström, Nyström, \& Angerbjörn, 2014; Mechnikova, 2009; Osmolovskaya, 1948; Therrien, Gauthier, Korpimäki, \& Bêty, 2014). In areas with small rodent cycles, the number of breeding pairs and the breeding success vary greatly from year to year following prey densities (Sundell et al., 2004; Terraube et al., 2015; Therrien et al., 2014). It has been suggested that buzzards are nomadic raptors, searching over large areas for favorable conditions with high abundance of small rodents (Sundell et al., 2004; Tast, Kaikusalo, \& Lagerström, 2010). In years of low small rodent densities, they may not reproduce and abandon the breeding area early (Wiklund, Angerbjörn, Isakson, Kjellen, \& Tannerfeldt, 1999). Clutch size usually depends on the abundance of prey, but chick survival and breeding success are more affected by climatic conditions, in particular heavy rainfall during the nestling period, and by the location of nests (Beardsell, Gauthier, Therrien, \& Bety, 2016; Pokrovsky et al., 2012; Potapov, 1997).

Buzzards prey both on lemmings and voles, and can breed relying exclusively on lemmings (Beardsell et al., 2016) or exclusively on voles (Terraube et al., 2015). However, Hellström et al. (2014) showed that in northern Sweden, the functional response of buzzards to Norwegian lemmings (Lemmus lemmus) was steeper than the response to grey-sided voles (Myodes rufocanus), reflecting a clear preference for lemmings. Changes in the relative abundance of prey, which can arise if climate change affects one prey species, such as lemmings, more than others, for instance voles (Ims et al., 2011), are likely to modify the relationship between prey and predator. Despite generally behaving as small rodent specialists, buzzards can also use alternative prey such as willow ptarmigan (Lagopus lagopus) or waterfowl as main breeding resources, if these are sufficiently abundant (Pokrovsky et al., 2014; Springer, 1975). Moreover, it has recently been documented that buzzards breed regularly on Kolguev Island where small rodents are completely absent and goslings (Anser spp. and Branta spp.) are the main prey during the breeding period in addition to willow ptarmigan (Kondratyev \& Zaynagutdinova, 2008; Pokrovsky et al., 2015). It is at present not clear whether these buzzards belong to distinct populations having adapted to use these alternative resources, or whether the species is in general quite resilient to changes in available prey.

The main aim of our study is to investigate whether the response of buzzards to small rodents changed in response to changes in composition and dynamics of the small rodent community. Specifically, we determined (a) how the buzzards responded numerically to small 
rodents, (b) how clutch size and breeding success of buzzards depended on the abundance of small rodents, and (c) how dietary selectivity of buzzards for the different small rodent species varied with their relative abundance. For each of these relationships, we investigated whether the response to lemmings differed from the response to the total abundance of small rodents, and whether the changes in the small rodent community modified the responses of the buzzards. We aimed in particular at determining to what degree buzzards, as rather flexible, moderately specialized predators, were affected by and/or adapting to changes in the dynamics of their preferred prey. Our results will contribute to understanding how resilient predators are to changes in the populations of their prey, and how this will affect the structure and functioning of tundra food webs in the future.

\section{2 | MATERIALS AND METHODS}

\section{1 | Study area}

The study was conducted at the Erkuta Tundra Monitoring Site in Russia from 1999 to 2017. The study area is located near the confluence of the Payuta and Erkuta rivers in the southern part of the Yamal Peninsula $\left(68.2^{\circ} \mathrm{N}, 69.2^{\circ} \mathrm{E}\right)$, in the low arctic shrub tundra. It is characterized by flat tundra interspersed with hills (up to $40 \mathrm{~m}$ high) with some steep slopes, and sandy cliffs along river banks and lakes (Sokolov, Ehrich, Yoccoz, Sokolov, \& Lecomte, 2012). The landscape is subdivided by a dense network of rivers and lakes (Figure 1), and

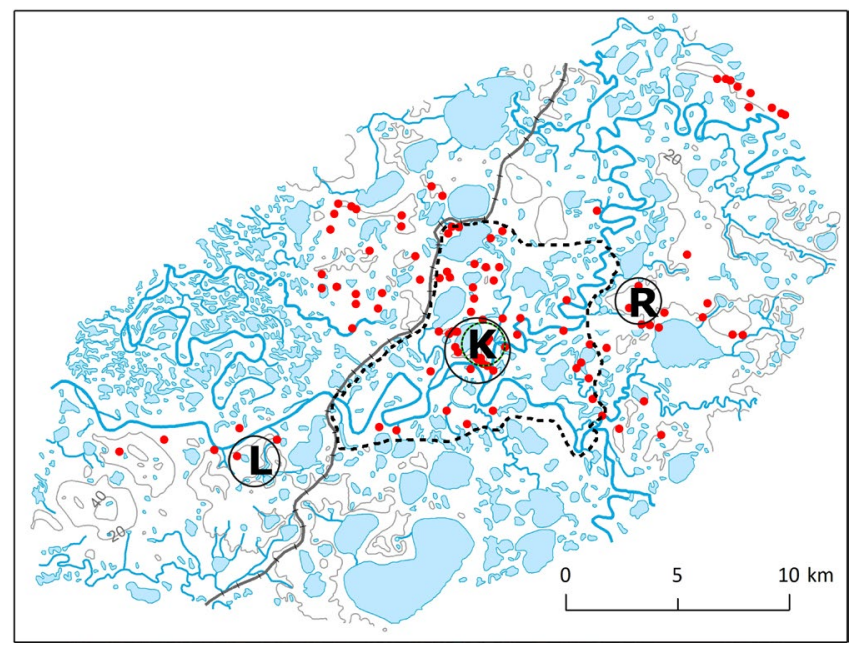

FIGURE 1 Map of the study area at the Erkuta Tundra Monitoring Site in southern Yamal, Russia. The area surrounded by a dashed line indicates the initial $100 \mathrm{~km}^{2}$ study area. In addition to this core area, the cliff at the northeastern edge of the main study area was surveyed in some of the earlier years (2001, 2004, and 2005). The small circle with a dashed line (K) shows the small rodent trapping area used from 1999 to 2006 . The circles with solid lines ( $(\mathrm{K}, \mathrm{K}$, and $\mathrm{R}$ ) indicate the trapping areas used after that. $\mathrm{K}$ and $R$ were used from 2007 to 2017, and L was used in 2012-2017. Red dots indicate the locations of all nests of rough-legged buzzards recorded during the study many low-lying areas are flooded in spring. Based on data from the CRU TS 4.01 spatial climatic dataset (Harris, Jones, Osborn, \& Lister, 2014), mean July temperature during the study period was $13^{\circ} \mathrm{C}$. The vegetation is composed of erect dwarf shrub tundra, low shrub tundra, Sphagnum-rich wetlands, and dense patches of willow thickets, which can be over $2 \mathrm{~m}$ high (Ehrich et al., 2012).

The small rodent community is composed of four main species: the narrow-headed vole (Microtus gregalis), Middendorff's vole (Microtus middendorffi), the collared lemming (Dicrostonyx torquatus), and the Siberian lemming (Lemmus sibiricus; Sokolova et al., 2014). At present, voles are the dominating species, with the narrow-headed vole as the most abundant. Other herbivores include mountain hare (Lepus timidus), muskrat (Ondatra zibethica), willow ptarmigan, and domestic reindeer (Rangifer tarandus). Several species of geese (mostly white-fronted geese, Anser albifrons) are breeding in the area at low numbers. Main predators, in addition to the rough-legged buzzard, are arctic fox, peregrine falcon (Falco peregrinus), long-tailed and arctic skua (Stercorarius longicaudus, S. parasiticus), and small mustelids (Mustela erminea and M. nivalis; Sokolov, Sokolova, Ims, Brucker, \& Ehrich, 2016).

\subsection{Small rodent abundance}

An abundance index of small rodents was obtained each year from snap trapping. For 1999-2006, trapping was carried out on lines of approximately 50 or 100 traps placed at $5 \mathrm{~m}$ intervals in several habitats for a minimum of two nights (Sokolov, 2003). Trap lines were situated in the core of the study area (Figure 1). Trapping was conducted from July to September in 1999, only in July in 2000 , and in June and July from 2001 to 2006. The number of trap nights per year varied from 200 to 2,410 (mean $=905$; Table S1). Since 2007 , small rodents were trapped in the second part of June and in the beginning of August according to the small quadrat method (Myllymäki, Paasikallio, Pankakoski, \& Kanervo, 1971) in three habitat types (willow thicket edge, mesic dwarf shrub tundra, and wetlands) as described in Sokolova et al. (2014). From 2007 to 2011, we used permanent small quadrats placed in two spatial units for two nights per season ( 2 units $\times 3$ habitats $\times 6$ quadrats $\times 12$ traps $\times 2$ nights $\times 2$ sessions $=1,728$ trap nights per year; in 2007 and 2016, only one session was carried out for logistic reasons; Table S1). In 2012 , a third unit consisting of quadrats in the same habitats was established (resulting in a total of 2,592 trap nights per year; Figure 1). Traps were baited with raisins and rolled oats. The trapping data were summarized as yearly abundance indices consisting of the number of animals trapped per 100 trap nights.

The two trapping protocols were used in parallel during 6 years (2010-2015), allowing to compare abundance indices. This comparison revealed that trap lines consistently yielded higher numbers of animals trapped per effort. Systematic differences in yield resulting from the configuration of the trapping design were examined by Fauteux et al. (2018). Their results showed that a group of three traps corresponded approximately to the effort of two single traps. Therefore, to assemble our data series, we reduced the trapping 
effort of the small quadrat data with 0.67-a correction, which resulted in a better fit between the two methods. To assess how robust our results are to the change in trapping protocol, we assembled an alternative time series using the trap lines for 1999-2006 and 2010-2015 and the same correction factor. All analyses were carried out with both small rodent datasets, and the results led to the same conclusions (Appendix S1, Table S4).

Periodicity of the total small rodent abundance index was assessed based on an autocorrelation plot of the detrended time series. We estimated trends in total abundance and abundance of the main species as coefficients of linear regressions of abundance against time, and a trend in the amplitude of population fluctuations was estimated from coefficients of variation calculated for a 5-year time window (linear model with autocorrelation, package nlme in $\mathrm{R})$. The two species of lemmings were combined to one abundance index for most of the analyses, because it was not possible to analyze Siberian lemmings separately due to their very low numbers.

\section{3 | Nesting and diet of buzzards}

Breeding of rough-legged buzzards was surveyed from the middle of June to the middle of August each year. To assess density, we searched for nests by walking through the study area targeting sites where nests had been observed in previous years, and places with similar habitat. In Yamal, buzzards can breed on cliffs, gentle slopes, or even in flat tundra (Sokolov, 2003). Buzzards exhibit conspicuous territorial behavior and when such behavior was detected, a systematic nest search was carried out. Coordinates of each nest were determined with a handhold GPS and breeding density was estimated each year relative to the study area. The size of the study area varied between 100 and $130 \mathrm{~km}^{2}$ in the earlier years, and was gradually increased to $250 \mathrm{~km}^{2}$, which are surveyed since 2012 (Table S2).

For each nest, we recorded the number of eggs laid (only four nests were found after hatching). If possible, nests were revisited to determine hatching and the survival of chicks until fledging. Hatching was considered successful, if at least one chick was observed in the nest. Brood size was defined as the number of chicks that survived until an age of approximately 3 weeks, when they reached a size at which they could be ringed.

The diet of buzzards was determined through the dissection of pellets. Pellets were collected throughout the study area mainly from cliffs, small hillocks, and close to nests. Except for the nests, the places where pellets were collected were almost the same every year. Pellets were dissected in the laboratory and all undigested segments of prey were determined by means of specific features of bones, feathers, teeth, etc. If possible, rodent remains were determined to species based on the enamel pattern of the first lower molar according to Borodin (2009).

\section{4 | Statistical analysis}

All statistical analyses were carried out in $\mathrm{R}$ version 3.5.0 ( $\mathrm{R}$ Core Team, 2018). The numerical response of buzzards to small rodent abundance was analyzed with generalized linear models (GLM) with a Poisson distributed error and the number of nests found each year as response variable. The size of the study area each year was included as an offset. A possible temporal change in the numerical response could be gradual or occur at a specific time resulting from a regime shift. Therefore, we created a factor with two levels corresponding to two distinct periods as explanatory variable (period) in addition to continuous time. The break between the two periods was determined based on the data as the year, for which the residual deviance of the model was smallest. Thus, predictor variables were the total small rodent abundance index, the abundance index for lemmings, year, and period. Six candidate models were assembled and compared with Akaike's information criterion corrected for small sample size $\left(\mathrm{AIC}_{\mathrm{c}}\right.$ ): a model with small rodent abundance, a model with lemming abundance, and models, which included small rodents and year or period, and a possible interaction between the two variables. We did not include models with year or period and lemming abundance, because only very few lemmings were trapped in recent years. Model fit was assessed graphically. Because theoretically the numerical response of predators is nonlinear, we specifically checked for indications of nonlinearity or thresholds of the response over the range of the predictor value. The function dispersiontest of the package AER (Kleiber \& Zeileis, 2008) was used to test for overdispersion. The small rodent and lemming indices were log transformed to achieve normal distribution of residuals. As there were 0 lemmings trapped in some years, for lemmings, 0.017 was added to the abundance index, which corresponds to half of the minimum which could have been trapped (Fauteux et al., 2018). For the best model, we report parameter estimates and confidence intervals. Because the increase in the study area could have caused changes in habitat quality, which might have influenced breeding density, we repeated the analysis taking into account only the nests found in the initial study area of $100 \mathrm{~km}^{2}$.

Breeding effort (clutch size), hatching success, and brood size were analyzed using a similar approach and the same combination of explanatory variables and candidate models as for nest density (but no offset). As previous studies have shown that rainfall is important for brood survival (Beardsell et al., 2016; Potapov, 1997), we included the mean July rainfall (CRU TS 4.01 spatial climatic dataset; Harris et al., 2014) as additive effect in all models for brood size. As any recorded breeding attempt per definition included at least one egg, a truncated Poisson distribution was used for the number of eggs (function vglm of the package VGAM in R; Yee, 2015). Hatching success was modelled using a GLM with a binomial error distribution and hatching was considered successful if at least one egg in the nest hatched. Brood size was modelled with a Poisson error distribution and analyzed only for nests that had hatched successfully. Model fit was assessed as above.

The diet data were summarized as the proportion of each small rodent species among all individual small rodents identified in the dissected pellets. Prey selectivity was defined as the proportion of consumed prey relative to the proportion of available prey, not necessarily assuming active selection by the predator. We 
calculated selection ratios for lemmings (both species together), Middendorff's voles, and narrow-headed voles as the proportion of individuals of the species identified in pellets each year divided by its proportion in the trapping data. To assess a possible change in prey preference over time, we calculated the standardized selection ratio $\alpha$ for each year (Equation 1, where $r_{i}$ is the proportion of prey $i$ in the diet, $n_{i}$ the proportion of prey $i$ in the environment, and $m$ the number of species; Hellström et al., 2014; Manly, Miller, $\&$ Cook, 1972). If each prey is used proportionally to its availability $\alpha=1 / m$. Higher $\alpha$ reveals preference. Linear regressions were used to test for changes of selection ratios over time.

$$
\alpha_{i}=r_{i} / n_{i} \times \frac{1}{\sum_{j=1}^{m} r_{j} / n_{j}} .
$$

\section{3 | RESULTS}

\subsection{Small rodents}

After correcting for the change in protocol, the trapping index varied between 0 in 2006 and 12.6 in 1999 relative to 100 trap nights carried out according to the small quadrat method (18.9 in 1999 based on the original data from the trap lines). The total abundance index was above 10 only in 1999. After this, fluctuations were of lower amplitude with small peaks of abundance every 3-5 years. Autocorrelation plots for the detrended time series revealed no significant autocorrelations for the total small rodent abundance or for each of the Microtus vole species. Until 2007, Middendorff's voles were the most abundant species, and after that, narrow-headed voles predominated (Figure S1). The lemmings exhibited two peaks with a 5-year interval in the beginning of the study, but remained at low densities after that. Siberian lemmings were mostly trapped in 1999 and 2005, and not a single individual was caught after 2009. Collared lemmings were most abundant in 1999 and 2004, but were present in the trapping data at low frequency during the whole study period.

Overall, there was a negative, but not statistically significant, trend in the total small rodent abundance index (slope $=-0.20$, $S E=0.11, p=.08$ ). Considering the main species, the data showed a decrease in lemmings (both species together) and in Middendorff's vole (lemmings: slope $=-0.05, S E=0.02, p=.03$; Middendorff's vole: slope $=-0.26, S E=0.08, p=.01)$. At the same time, the abundance of narrow-headed voles increased (slope $=0.09, S E=0.03, p=.02$ ). There was thus a significant shift in small rodent community composition. The amplitude of abundance fluctuations estimated as coefficient of variation did not change significantly over the study period (slope $=-0.03, S E=0.02, p=.20$ ), but the suggested negative trend was compatible with a fading out of the small rodent cycle.

\subsection{Buzzard breeding}

In total, 104 buzzard nests were recorded during the study period. The maximum number of nests was observed in 1999 with 16 nests, whereas in 2007, no nests were found at all (no observations were carried out in 2006). The density of buzzard nests decreased considerably over the study period, and the observed decrease was even stronger when taking into account only nests found in the initial study area of $100 \mathrm{~km}^{2}$ (Figure 2).

Nest density varied with small rodent abundance (Figure 2). A model with an additive effect of the small rodent index and period received most support from $\mathrm{AIC}_{\mathrm{c}}$ (Table S3). Dividing the study period after 2004 yielded the models with the lowest residual deviance; therefore, we defined the "early" period as 1999-2004 and the "recent" period as 2005-2017. A subdivision after 2005 or 2006 received nearly as much support (difference in residual deviance $=0.35$ ). On average, nest density doubled for an increase of one in the log of small rodent abundance ( $95 \%$ confidence interval $[\mathrm{Cl}]=1.55-2.94$; Figure $3 \mathrm{a}$ ), and nest density relative to small rodent abundance was reduced by a factor of 0.45 after 2004 $(\mathrm{Cl}=0.29-0.71)$. The distribution of residuals was satisfactory and the model did not show any signs of overdispersion. There was no indication of nonlinearity in the residuals and the overlap in the small rodent abundance index between the two periods makes it unlikely that the effect of period is due to a nonlinear numerical response over the range of values included. According to $\mathrm{AIC}_{c}$, the next best model included small rodent abundance and an additive effect of year (difference in $\mathrm{AIC}_{\mathrm{c}} \Delta \mathrm{AIC}_{\mathrm{c}}=1.66$; Table S3), showing a congruent result of a positive effect of small rodents with a decrease of density over time by a factor of $0.94(\mathrm{Cl}=0.90-0.98)$
FIGURE 2 Density of rough-legged buzzard nests is plotted together with the small rodent abundance index resulting from snap trapping (black circles and red triangles, respectively). Because the size of the study area increased over the study period, the number of nests found in the initial study area $\left(100 \mathrm{~km}^{2}\right)$ is shown in addition (gray squares with dotted line). The two different designs used for the small rodent trapping are indicated at the top of the figure

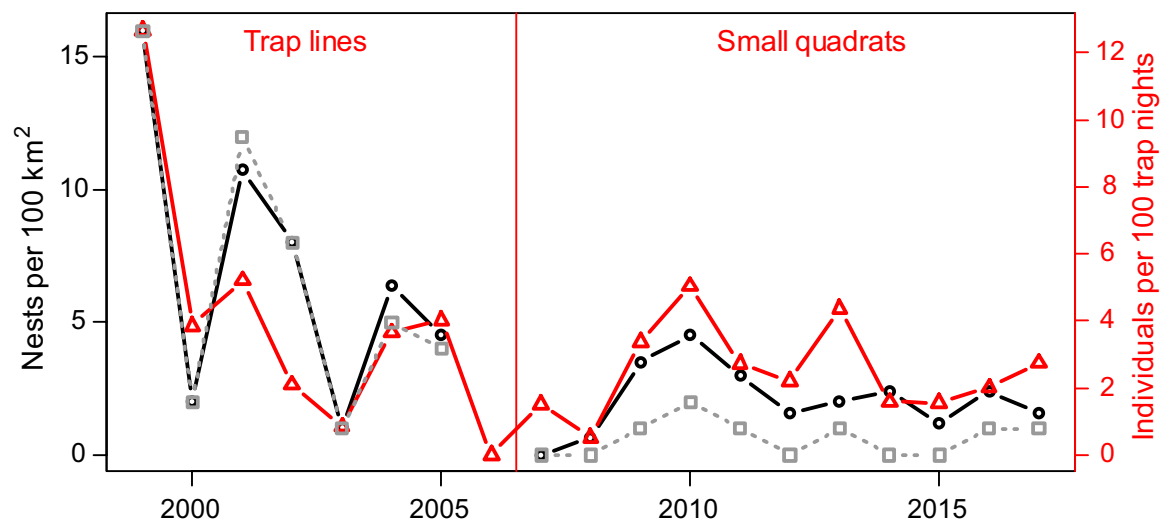


(a)

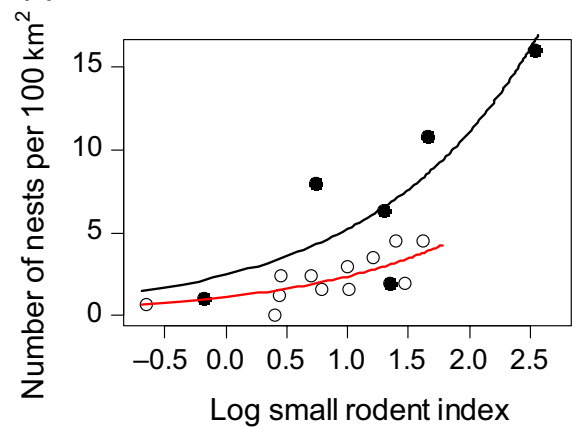

(c)

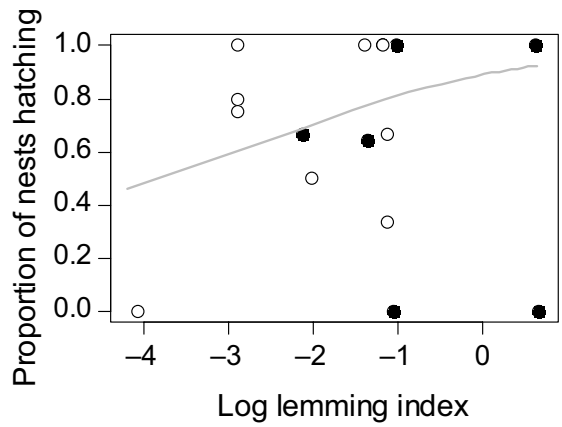

(b)

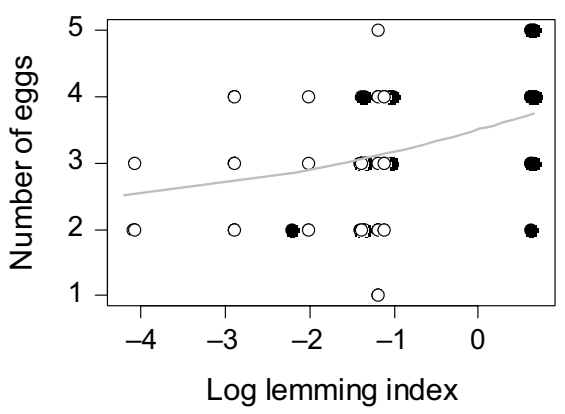

(d)

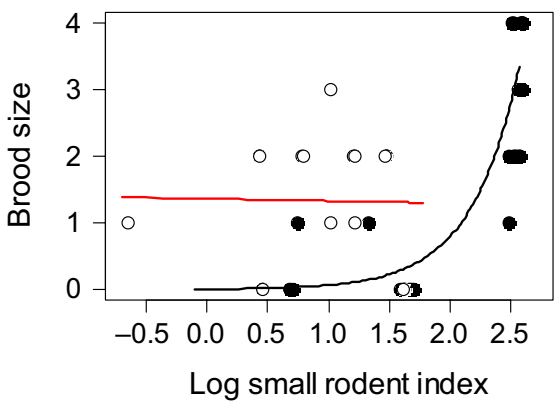

FIGURE 3 Relationships of demographic rates of rough-legged buzzards to small rodent abundance as predicted by the most parsimonious models are plotted together with the observed values. Dots represent data from the period 1999-2004 whereas open circles refer to 2005-2017. (a) Breeding density relative to the total small rodent abundance index. The black line refers to the response before the shift in small rodent dynamics and community composition, whereas the red line refers to the more recent period. (b) Clutch size relative to the lemming index. (c) Hatching success relative to the lemming index. (d) Brood size relative to the total small rodent index (colors as in a). Small rodent indices are on the log scale on all plots per year. A model with lemming abundance explained the data considerably less well $\left(\triangle \mathrm{AIC}_{\mathrm{c}}=28.88\right)$. Analyzing breeding density only in the initial study area of $100 \mathrm{~km}^{2}$ gave qualitatively similar results, but the decrease in breeding density after 2004 was stronger (Table S5).

Average yearly clutch size varied between 2 and 4 (overall mean $=3.1, S D=0.95)$ and the maximal clutch size observed was 5. The variation in clutch size was best explained by a model with the log of lemming abundance as explanatory variable $(\triangle \mathrm{AIC}$ to the next best model $=4.45$; Table S3). It indicated a moderate increase in clutch size by a factor of $1.13(\mathrm{Cl}=1.02-1.24)$ for an increase in 1 in the log of lemming abundance (Figure $3 b$ ). For hatching success, the model with the log of lemming abundance received most support from $\operatorname{AIC}_{\mathrm{c}}\left(\triangle \mathrm{AIC}_{\mathrm{c}}\right.$ for total small rodent abundance $\left.=4.06\right)$ and indicated a positive effect of lemming abundance on hatching success $(0.65, \mathrm{Cl}=0.24-1.12$ on the logit scale; Figure 3c). Inspecting the data revealed, however, that this effect was only due to the year 2016, when none of the six recorded nests hatched and no lemmings were caught. Without this extreme year, there was no effect of lemming abundance on hatching success (Table S3).

The number of chicks surviving until fledging varied a lot between years. In the peak year of 1999 , all nests produced at least one fledgling, the maximal brood size was 4 , and a total of 43 fledglings were produced in the $100 \mathrm{~km}^{2}$ study area. In 2001 or in 2014 , on the contrary, all chicks died. The number of fledglings per $100 \mathrm{~km}^{2}$ after 1999 varied between 0 and 3.2. On average, brood size in nests which had hatched successfully was 1.55 until 2005 and 1.36 after that, and did not differ significantly between the periods ( $t$ test: $t=0.52, p=.6$ ). A model with small rodent abundance, period, and an interaction between the two predictors in addition to total rainfall in July received clear support from $\mathrm{AIC}_{\mathrm{c}}$ $\left(\triangle \mathrm{AIC}_{\mathrm{c}}=5.66\right)$. This model indicated that there was a significant positive effect of rodent abundance on the number of fledglings until 2004 but not after that (Figure 3d). Taking into account small rodent abundance, the number of fledglings was, however, significantly higher after 2004 than in the period before that. Inspecting the data for influencial values showed that the strong positive effect in the earlier period was due only to the peak year in 1999, whereas brood size in the other years was low. Without this year, the interaction model was not better than a simpler additive model $\left(\triangle A I C_{c}=1.36\right.$ for the interaction model). The latter showed no effect of small rodent abundance over the more narrow range of density fluctuations after 1999 , or of total July precipitation, on the number of fledglings. There was, however, a clear increase of the number of fledglings in the recent period (estimate on the log scale $=2.08, \mathrm{Cl}=0.79-3.94)$.

\section{3 | Buzzard diet}

The pellet dissection revealed that four species of small rodents, the two lemming species and the two Microtus voles, constituted the main part of the buzzard's diet. Altogether, we identified remains of 4,307 individual small rodents representing $88 \%$ of all identified prey items (Table 1). Pellet dissection is, however, a method that is likely to underestimate the presence of larger prey in the diet, from which mostly meat is consumed (Francksen, Whittingham, \& Baines, 2016; Pokrovsky et al., 2014). For birds, we counted one individual when feathers or other remains were found, although these could belong to several individuals. Because our study focusses on the response of buzzards to changes in small 
rodent community composition, we limited the statistical analyses of dietary preferences to small rodents. As red-backed voles (Myodes rutilus) occurred only at very low frequencies, they were also excluded from these analyses.

Comparing the proportions of small rodent species in the diet data to their relative availability as estimated by trapping revealed a clear preference for lemmings. Remains of both species were found in the pellets every year, although Siberian lemmings were less frequent than collared lemmings, as in the trapping data (Figure S2). Because of the low abundance of Siberian lemmings, both species were pooled for the diet analyses. The proportion of lemmings in the pellet data was higher than their proportion among trapped individuals in all years (Figure 4a), although it declined toward the end of the study period together with the decline in lemming abundance (Figure S2). The two Microtus voles were consumed proportionally to their availability at low proportions, but they were underrepresented at high relative abundance (Figure 4b,c). This was true during the whole study period.

TAB LE 1 Total number and percentage of rodent prey identified in pellets of rough-legged buzzards in the period 1999-2016

\begin{tabular}{|lcc|}
\hline Species & $\begin{array}{l}\text { Number } \\
\text { of prey }\end{array}$ & Percent \\
\hline Collared lemming & 1,822 & 37 \\
\hline Siberian lemming & 290 & 6 \\
\hline Narrow-headed vole & 1,004 & 20 \\
\hline Middendorff's vole & 1,161 & 24 \\
\hline Red-backed vole & 30 & 1 \\
\hline Unidentified Microtus vole & 291 & 6 \\
\hline Unidentified small rodents & 265 & 5 \\
\hline Muskrat & 46 & 1 \\
\hline
\end{tabular}

Accordingly, the selection ratio $\alpha$ was above one-third for lemmings during the whole study period (showing preference), and below for the two Microtus vole species (Figure 4d). For lemmings and for Middendorff's vole, there was no trend in $\alpha$ over the study period. For narrow-headed voles, the species which increased in abundance according to the trapping data, $\alpha$ decreased by 0.012 per year over the study period $(p=.02)$.

\section{4 | DISCUSSION}

Using data on breeding activity of rough-legged buzzards over 19 years, we documented a change in the response of demographic rates of buzzards to small rodent density over a period where the small rodent community experienced a dampening in the amplitude of density fluctuations and a shift in species composition. The density of breeding pairs in the study area was positively related to small rodent abundance. However, after a shift from lemmings and Middendorff's voles to more narrow-headed voles after 2004-2006, the number of buzzard nests relative to small rodent abundance became lower. The clear preference of buzzards for lemmings over the whole study period revealed by the diet data indicates that the decrease of lemmings may be a cause of this decrease in breeding density. Over the whole study period, clutch size was also positively related to lemming abundance. Except for the peak year 1999, brood size was not related to small rodent abundance, but interestingly brood size relative to the small rodent index was higher in the recent period than in earlier years.

These observations suggest that, although less buzzards were breeding in the area after the changes in the small rodent community composition, the remaining pairs had on average a higher
FIGURE 4 Prey selectivity of roughlegged buzzards in relation to small rodent abundance. (a) Selection ratios for lemmings (Siberian and collared lemmings together); (b) selection ratios for narrowheaded vole; (c) selection ratios for Middendorff's vole; the black dotted line shows the boundary between selection and avoidance. (d) Standardized selection ratios according to Equation 1. Blue circles, green squares, and red triangles display lemmings, narrow-headed voles, and Middendorff's voles, respectively (a)

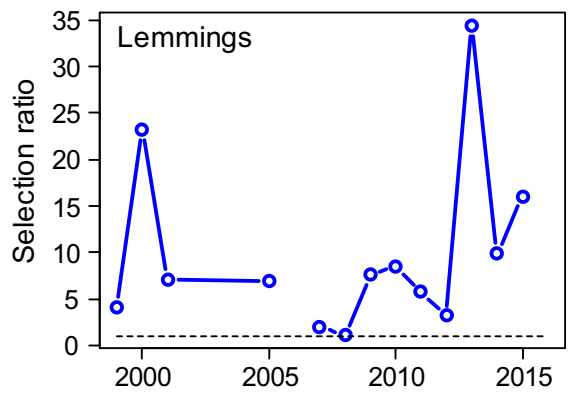

(c)

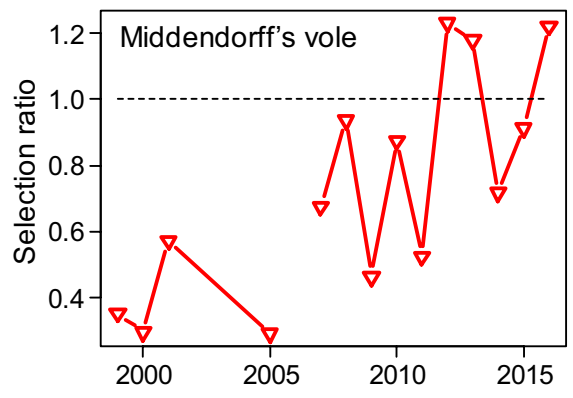

(b)

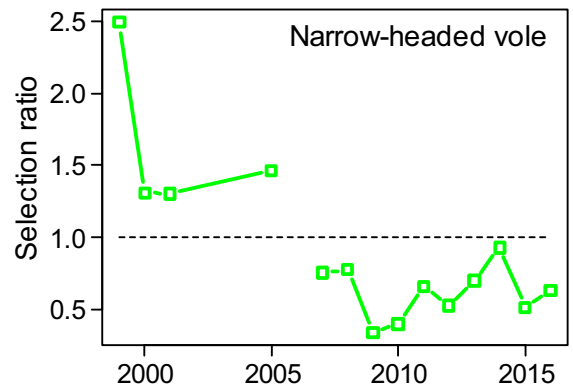

(d)

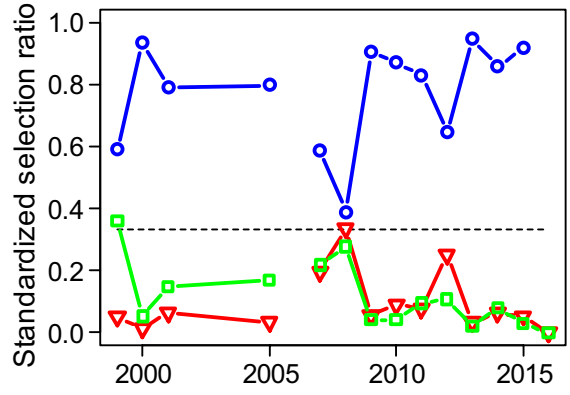


reproductive success than at similar small rodent abundances in the earlier years. It could be that these successful pairs are the more experienced birds in the population, and, therefore, breed and manage to raise a brood also in difficult conditions. Alternatively, they could be birds, which are better at using voles or other alternative resources, although still preferring lemmings, and therefore were better adapted to the new conditions. Alternatively, birds might be competing for the best territories, and these territories would be the only ones occupied in recent years. However, because breeding territories vary a lot between years in our study area, and there are no permanent nesting sites, we consider this rather unlikely. A shift in the population may also have occurred, as birds more dependent on lemmings abandoned the area to breed further North, and could have been replaced by birds more able to cope with low lemming abundances. Although we cannot distinguish between these different processes, our data suggest an adaptation of the buzzard population to changes in the small rodent community over a short time span, at the same time as densities in the study area clearly decreased.

\section{1 | Rough-legged buzzard breeding}

Studies from other areas in the Arctic showed that rough-legged buzzards can display variable dependence on small rodents as main resource. Thus, on Bylot Island, they behave as lemmings specialists showing a clear numerical response (Therrien et al., 2014). In northern Fennoscandia, they are small rodent specialists (Tast et al., 2010), with a preference for Norwegian lemmings as prey (Hellström et al., 2014). In other areas, however, they are less specialized and use birds, notably ptarmigan, as alternative prey in low small rodent years (Pokrovsky et al., 2014; Springer, 1975), or breed even in areas where small rodents are absent, such as on Kolguev Island (Pokrovsky et al., 2015). None of these studies documented; however, the reaction of a buzzard population to a change in resource availability over time, and it was therefore unclear how fast they could adapt to such changes locally.

A comparison among study areas reveals also considerable differences in demographic rates. Maximal densities on Bylot Island reached 15 pairs per $100 \mathrm{~km}^{2}$ (Therrien et al., 2014), which is about the same as the maximum observed in our study area in 1999 , in a year where lemmings were abundant. In that population, mean clutch size and mean brood size were also higher with 4.4 and 4.0, respectively (Beardsell et al., 2016), than in southern Yamal (mean clutch size $=3.1$ and mean brood size $=1.3$ ). In populations relying partly or completely on other prey than small rodents, both densities and clutch/brood size were lower and similar to the ones observed at Erkuta after 2005 (Pokrovsky et al., 2014, 2015). Particularly high breeding densities have been reported from Fennoscandia, where buzzards reached 25 pairs per $100 \mathrm{~km}^{2}$ in peak small rodent years (Hellström et al., 2014). In this area, small rodent densities were considerably higher than both on Bylot Island and in Yamal, and this community included Norwegian lemmings. These comparisons indicate that an adaptation to lower resource availability occurs at the cost of lower densities and reproductive output.

Weather, in particular heavy rainfall during the nestling period, is detrimental to the breeding success of northern raptors breeding in open nests (Anctil, Franke, \& Bety, 2014; Lehikoinen et al., 2009; Pokrovsky et al., 2012; Potapov, 1997). Our data, however, did not indicate a negative effect of rainfall on brood size. This may be because we used monthly total rainfall, as daily data were not available for our study area. Several authors documented indeed that particularly strong rain is harmful to the young raptor chicks (Anctil et al., 2014; Potapov, 1997). Observations from particular years confirm that this was also the case in our study area in some years. In 2001, for instance, all chicks died after a heavy rainstorm that lasted for 2 days.

\subsection{Changes in small rodent dynamics}

During the study period, we documented a decrease in lemmings and an increase in narrow-headed voles, at the same time as the amplitude of small rodent fluctuations faded out. Our data do not really allow to compare the two lemming species, but they indicate that the decline was most pronounced for Siberian lemmings. Although our observations covered only a few years before the change in dynamics, other sources report that 3-5 year high amplitude cycles were typical for small rodents in southern Yamal previous to 1990 (Danilov, 2000; Osmolovskaya, 1948). Moreover, both species of lemmings reached high abundances in southern Yamal until the 1990s, including in sites, which are more than $100 \mathrm{~km}$ south of our study area (Balakhonov, Danilov, Lobanova, \& Chibiryak, 1997; Danilov, 2000).

Similar small rodent community changes observed elsewhere in the Arctic have been attributed to climate change (Ims \& Fuglei, 2005). Shorter winters with less stable cold weather and warm spells with rain leading to ground icing are more detrimental to lemmings that depend on winter breeding under the snow to reach high densities, than to voles (Ims et al., 2011). Hard snow at the basis of the snow pack, which can result from warm weather and strong winds in fall, or rain-on-snow events later in winter, is particularly detrimental to growth of lemming populations in winter (Domine et al., 2018; Kausrud et al., 2008). Although not addressed by our study, similar processes might be suggested for our study area. Both spring and fall temperatures have indeed increased since the $1970 \mathrm{~s}$ based on interpolated monthly average values (Harris et al., 2014). Temperature increase was considerable in October $\left(0.94^{\circ} \mathrm{C}\right.$ per decade) as well as in the spring months April, May, and June (0.90, 0.89 , and $0.77^{\circ} \mathrm{C}$ per decade, respectively). Warmer falls might have increased the probability of wet snow, which freezes to a hard bottom layer remaining during the whole winter (Domine et al., 2018), whereas warmer springs and falls together result in a shorter winter season, a change which was hypothesized to have caused the collapse of lemming cycles in eastern Greenland (Gilg et al., 2009). Despite suggestive correlations, our data do not allow to determine the causes for the observed changes in the small rodent community. 
It is also possible that the change in dynamics is related to a change in species dominance driven by interactions within the community (Hanski \& Henttonen, 1996), or that it represents a low amplitude phase in a system with transient dynamics (Angerbjörn, Tannerfeldt, \& Lundberg, 2001).

\subsection{Changes in trophic relationships}

During the whole study period, both species of lemmings were clearly overrepresented in the buzzards diet relative to the small rodent trapping data. It is possible that lemmings were somewhat underrepresented in the trapping data, because some of the habitats, where the traps were set, were not optimal for lemmings. However, this is unlikely to explain the strong selection for lemmings in the diet. Moreover, a similar positive selection of lemmings has been observed in northern Sweden, in a small rodent community composed of Norwegian lemmings, grey-sided voles, and tundra voles (Microtus oeconomus). The key role lemmings play for arctic predators has also been demonstrated for other species such as arctic foxes or snowy owls in Fennoscandia (Ims et al., 2017). The preference of predators for lemmings may be related to their larger size providing more food per hunting effort, and possibly to the fact that they are easier to catch. The observation that clutch size was correlated with lemming abundance might suggest that buzzards use lemmings as a clue for years when it is worth to invest in a big clutch. Lemmings may also be more visible to avian predators than voles, particularly narrow-headed voles, who often live in willow thickets and dig burrow systems (Palchekh, Malkova, Kuzmin, \& Yakimenko, 2003; Sokolova et al., 2014). The decrease in the selection coefficient $\alpha$ over the study period supports the hypothesis that it is difficult for buzzards to exploit this increasing prey species.

Seasonal dynamics contribute also to the key role lemmings play for predators. Because they reproduce under the snow, lemmings reach indeed high densities already after snow melt, whereas vole densities increase over the course of summer (Ims \& Fuglei, 2005). Lemmings are thus available at the onset of the breeding period of predators. During the last 10 years, vole populations clearly increased over summer in our study area, whereas for lemmings, the seasonal pattern was not clear due to their very low densities (Ehrich et al., 2017).

In conclusion, we showed how the response of a moderately specialized predator to small rodent abundance changed with a possibly climate-driven change in small rodent dynamics and community composition. Our results confirm previous findings that changes in small rodent dynamics will be detrimental for arctic predators (Ims et al., 2017; Schmidt et al., 2012), but at the same time, they suggest that some predators will be able to partially adapt to these changes by modified responses of demographic rates to resource abundance. In order to understand the consequences of climate-driven ecosystem changes and predict future species distributions, a better understanding of trophic interactions and their plasticity is important. In the future, it would be interesting to investigate the relative roles of individual phenotypic plasticity versus individual differences or evolutionary changes in such processes.

\section{ACKNOWLEDGEMENTS}

Since 1999, our work was conducted in frame of state contract of Institute of Plant and Animal Ecology, Ural Branch, Russian Academy of Sciences (IF, AS, NS, VS). Our work was supported by the grants of Russian Fund of Basic Research \#18-05-60261, 18-54-15013 and 16-44-890108, Programs of UD RAS \#12-4-7022-Arctic, 18-9-4-22-Arctic, 15-15-4-35; by the project "Yamal EcoSystem" (362259) from the Terrestrial Flagship of the High North Research Centre for Climate and the Environment (Fram Centre), and by the Research Council of Norway, grant IPY "Arctic Predators." We thank the Laptander family, the company "Gazpromtrans," the NGO Russian Center of Development of the Arctic as well as numerous filed assistants for invaluable support to fieldwork, and Rolf A. Ims for inspiring discussions. The Governor of Yamal-Nenets Autonomous District, the Department of Science and Innovations and the Department of International relations of the Yamal Government have supported our work.

\section{ORCID}

Ivan A. Fufachev (iD https://orcid.org/0000-0002-9531-3127

Dorothee Ehrich (iD https://orcid.org/0000-0002-3028-9488

Natalia A. Sokolova (iD https://orcid.org/0000-0002-6692-4375

Vasiliy A. Sokolov iD https://orcid.org/0000-0002-0115-3151

Aleksandr A. Sokolov (D) https://orcid.org/0000-0002-1521-3856

\section{REFERENCES}

Anctil, A., Franke, A., \& Bety, J. (2014). Heavy rainfall increases nestling mortality of an arctic top predator: Experimental evidence and longterm trend in peregrine falcons. Oecologia, 174(3), 1033-1043. https ://doi.org/10.1007/s00442-013-2800-y

Angerbjörn, A., Tannerfeldt, M., \& Lundberg, H. (2001). Geographical and temporal patterns of lemming population dynamics in Fennoscandia. Ecography, 24(3), 298-308. https://doi. org/10.1034/j.1600-0587.2001.240307.x

Balakhonov, V. S., Danilov, A. N., Lobanova, N. A., \& Chibiryak, M. V. (1997). Population dynamics of small mammals in southern Yamal. In P. A. Kosintsev (Ed.), History and present state of the fauna of the north of Western Siberia. Collection of scientific papers (pp. 43-59). Chelyabinsk: Rifey.

Beardsell, A., Gauthier, G., Therrien, J. F., \& Bety, J. (2016). Nest site characteristics, patterns of nest reuse, and reproductive output in an Arctic-nesting raptor, the Rough-legged Hawk. The Auk, 133(4), 718-732. https://doi.org/10.1642/auk-16-54.1

Boonstra, R., Andreassen, H. P., Boutin, S., Hušek, J., Ims, R. A., Krebs, C. J., ... Wabakken, P. (2016). Why do the boreal forest ecosystems of Northwestern Europe differ from those of Western North America? BioScience, 66(9), 722-734. https://doi.org/10.1093/ biosci/biw080 
Borodin, A. W. (2009). Guide of the teeth of voles in the Urals and western Siberia (late Pleistocene - present). Ekaterinburg, Russia: Institute of Ecology of Plants and Animals, Ural Branch of the Russian Academy of Sciences.

Clavel, J., Julliard, R., \& Devictor, V. (2011). Worldwide decline of specialist species: Toward a global functional homogenization? Frontiers in Ecology and the Environment, 9(4), 222-228. https://doi. org/10.1890/080216

Cornulier, T., Yoccoz, N. G., Bretagnolle, V., Brommer, J. E., Butet, A., Ecke, F., ... Lambin, X. (2013). Europe-wide dampening of population cycles in keystone herbivores. Science, 340(6128), 63-66. https:// doi.org/10.1126/science.1228992

Danilov, A. N. (2000). Dynamics and spatial distribution of tundra rodents in southern Yamal. PhD thesis, Institute of Plant and Animal Ecology of Ural Branch of Russian Academy of Sciences, Ekaterinburg, Russia.

Domine, F., Gauthier, G., Vionnet, V., Fauteux, D., Dumont, M., \& Barrere, M. (2018). Snow physical properties may be a significant determinant of lemming population dynamics in the high Arctic. Arctic Science, 4(4), 813-826. https://doi.org/10.1139/as-2018-0008

Ehrich, D., Cerezo, M., Rodnikova, A. Y., Sokolova, N. A., Fuglei, E., Shtro, V. G., \& Sokolov, A. A. (2017). Vole abundance and reindeer carcasses determine breeding activity of Arctic foxes in low Arctic Yamal, Russia. BMC Ecology, 17, https://doi.org/10.1186/s12898-017-0142-z

Ehrich, D., Henden, J.-A., Ims, R. A., Doronina, L. O., Killengren, S. T., Lecomte, N., ... Yoccoz, N. G. (2012). The importance of willow thickets for ptarmigan and hares in shrub tundra: The more the better? Oecologia, 168(1), 141-151. https://doi.org/10.1007/ s00442-011-2059-0

Fauteux, D., Gauthier, D., Mazerolle, M. J., Coallier, N., Bêty, J., \& Berteaux, D. (2018). Evaluation of invasive and non-invasive methods to monitor rodent abundance in the Arctic. Ecosphere, 9(2), e02124. https://doi.org/10.1002/ecs2.2124

Francksen, R. M., Whittingham, M. J., \& Baines, D. (2016). Assessing prey provisioned to common buzzard Buteo buteo chicks: A comparison of methods. Bird Study, 63(3), 303-310. https://doi.org/10.1080/00063 657.2016.1183111

Gilg, O., Hanski, I., \& Sittler, B. (2003). Cyclic dynamics in a simple vertebrate predator-prey community. Science, 302(5646), 866-868.

Gilg, O., Sittler, B., \& Hanski, I. (2009). Climate change and cyclic predator-prey population dynamics in the high Arctic. Global Change Biology, 15(11), 2634-2652.

Hanski, I., \& Henttonen, H. (1996). Predation on competing rodent species: A simple explanation of complex patterns. Journal of Animal Ecology, 65(2), 220-232. https://doi.org/10.2307/5725

Harris, I., Jones, P. D., Osborn, T. J., \& Lister, D. H. (2014). Updated highresolution grids of monthly climatic observations-The CRU TS3.10 dataset. International Journal of Climatology, 34(3), 623-642. https:// doi.org/10.1002/joc.3711

Hellström, P., Nyström, J., \& Angerbjörn, A. (2014). Functional responses of the rough-legged buzzard in a multi-prey system. Oecologia, 174(4), 1241-1254. https://doi.org/10.1007/s00442-013-2866-6

Ims, R. A., \& Fuglei, E. (2005). Trophic interaction cycles in tundra ecosystems and the impact of climate change. BioScience, 55(4), 311-322. https://doi.org/10.1641/0006-3568(2005)055[0311:TICITE]2.0.CO;2

Ims, R. A., Henden, J. A., \& Killengreen, S. T. (2008). Collapsing population cycles. Trends in Ecology \& Evolution, 23, 79-86. https://doi. org/10.1016/j.tree.2007.10.010

Ims, R. A., Killengreen, S. T., Ehrich, D., Flagstad, Ø., Hamel, S., Henden, J.-A., ... Yoccoz, N. G. (2017). Ecosystem drivers of an Arctic fox population at the western fringe of the Eurasian Arctic. Polar Research, 36(sup1), 8. https://doi.org/10.1080/17518369.2017.1323621

Ims, R. A., Yoccoz, N. G., \& Killengreen, S. T. (2011). Determinants of lemming outbreaks. Proceedings of the National Academy of Sciences of the United States of America, 108(5), 1970-1974. https://doi. org/10.1073/pnas.1012714108
Kausrud, K. L., Mysterud, A., Steen, H., Vik, J. O., Østbye, E., Cazelles, B., ... Stenseth, N. C. (2008). Linking climate change to lemming cycles. Nature, 456(7218), 93-97. https://doi.org/10.1038/nature07442

Kleiber, C., \& Zeileis, A. (2008). Applied econometrics with R. New York, NY: Springer-Verlag.

Koltz, A. M., Classen, A. T., \& Wright, J. P. (2018). Warming reverses top-down effects of predators on belowground ecosystem function in Arctic tundra. Proceedings of the National Academy of Sciences of the United States of America, 115(32), E7541-E7549. https://doi. org/10.1073/pnas.1808754115

Kondratyev, A., \& Zaynagutdinova, E. (2008). Greater white-fronted Geese Anser albifrons and Bean Geese A. fabalis on Kolguev IslandAbundance, habitat distribution, and breeding biology. Vogelwelt, 129, 326-333.

Krebs, C. J. (2011). Of lemmings and snowshoe hares: The ecology of northern Canada. Proceedings of the Royal Society B-Biological Sciences, 278(1705), 481-489. https://doi.org/10.1098/rspb.2010.1992

Lehikoinen, A., Byholm, P., Ranta, E., Saurola, P., Valkama, J., Korpimäki, E., ... Henttonen, H. (2009). Reproduction of the common buzzard at its northern range margin under climatic change. Oikos, 118(6), 829836. https://doi.org/10.1111/j.1600-0706.2008.17440.x

Manly, B. F. J., Miller, P., \& Cook, L. M. (1972). Analysis of a selective predation experiment. The American Naturalist, 106(952), 719-736. https ://doi.org/10.1086/282808

Martin, T. E. (2007). Climate correlates of 20 years of trophic changes in a high-elevation riparian system. Ecology, 88(2), 367-380. https://doi. org/10.1890/0012-9658(2007)88[367:Ccoyot]2.0.Co;2

Mechnikova, S. A. (2009). Raptors of southern Yamal: Breeding ecology and population dynamics. PhD thesis, Moscow State Pedagogical University, Moscow. [in Russian]

Millon, A., Petty, S. J., Little, B., Gimenez, O., Cornulier, T., \& Lambin, X. (2014). Dampening prey cycle overrides the impact of climate change on predator population dynamics: A long-term demographic study on tawny owls. Global Change Biology, 20(6), 1770-1781. https://doi. org/10.1111/gcb.12546

Mortensen, L. O., Schmidt, N. M., Høye, T. T., Damgaard, C., \& Forchhammer, M. C. (2016). Analysis of trophic interactions reveals highly plastic response to climate change in a tri-trophic High-Arctic ecosystem. Polar Biology, 39(8), 1467-1478. https://doi.org/10.1007/ s00300-015-1872-z

Myllymäki, A., Paasikallio, A., Pankakoski, E., \& Kanervo, V. (1971). Removal experiments on small quadrats as a means of rapid assessment of the abundance of small mammals. Annales Zoologici Fennici, 8(1), 177-185.

Osmolovskaya, V. I. (1948). Ecology of birds of prey in the Yamal peninsula. Proceedings of the Geographic Institute, Academy of Sciences USSR, 41, 5-77. [in Russian]

Palchekh, N. A., Malkova, M. G., Kuzmin, I. V., \& Yakimenko, V. V. (2003). The structure of narrow-skulled vole (Microtus gregalis Pall.) colonies in Western Siberia. Russian Journal of Ecology, 34, 327-331. [in Russian]

Pokrovsky, I., Ehrich, D., Ims, R. A., Kondratyev, A. V., Kruckenberg, H., Kulikova, O., ... Shienok, A. (2015). Rough-legged buzzards, Arctic foxes and red foxes in a tundra ecosystem without rodents. PLoS ONE, 10(2), e0118740. https://doi.org/10.1371/journal.pone.0118740

Pokrovsky, I., Ehrich, D., Ims, R. A., Kulikova, O., Lecomte, N., \& Yoccoz, N. G. (2012). Assessing the causes of breeding failure among the rough-legged buzzard (Buteo lagopus) during the nestling period. Polar Research, 31, 17294. https://doi.org/10.3402/polar.v31i0.17294

Pokrovsky, I., Ehrich, D., Ims, R. A., Kulikova, O., Lecomte, N., \& Yoccoz, N. G. (2014). Diet, nesting density, and breeding success of roughlegged buzzards (Buteo lagopus) on the Nenetsky Ridge, Arctic Russia. Polar Biology, 37(4), 447-457. https://doi.org/10.1007/ s00300-013-1441-2

Potapov, E. R. (1997). What determines the population density and reproductive success of rough-legged buzzards, Buteo 
lagopus, in the Siberian tundra? Oikos, 78(2), 362-376. https://doi. org/10.2307/3546304

R Core Team (2018). R: A language and environment for statistical computing. Vienna, Austria: R Foundation for Statistical Computing. Retrieved from https://www.R-project.org/

Schmidt, N. M., Hardwick, B., Gilg, O., Høye, T. T., Krogh, P. H., Meltofte, H., ... Roslin, T. (2017). Interaction webs in arctic ecosystems: Determinants of arctic change? Ambio, 46, S12-S25. https://doi. org/10.1007/s13280-016-0862-x

Schmidt, N. M., Ims, R. A., Høye, T. T., Gilg, O., Hansen, L. H., Hansen, J., \& Sittler, B. (2012). Response of an arctic predator guild to collapsing lemming cycles. Proceedings of the Royal Society B-Biological Sciences, 279(1746), 4417-4422. https://doi.org/10.1098/ rspb. 2012.1490

Sokolov, A. A. (2003). Functional relationships between the Roughlegged Buzzard (Buteo lagopus) and small rodents in the southern shrub tundra of Yamal. PhD thesis, Ekaterinburg, Russia. [in Russian]

Sokolov, A. A., Sokolova, N. A., Ims, R. A., Brucker, L., \& Ehrich, D. (2016). Emergent rainy winter warm spells may promote boreal predator expansion into the arctic. Arctic, 69(2), 121-129. https://doi. org/10.14430/arctic4559

Sokolov, V., Ehrich, D., Yoccoz, N., Sokolov, A., \& Lecomte, N. (2012). Bird communities of the Arctic shrub tundra of Yamal: Habitat specialists and generalists. PLoS ONE, 7, e50335. https://doi.org/10.1371/journ al.pone.0050335

Sokolova, N. A., Sokolov, A. A., Ims, R. A., Skogstad, G., Lecomte, N., Sokolov, V. A., ... Ehrich, D. (2014). Small rodents in the shrub tundra of Yamal (Russia): Density dependence in habitat use? Mammalian Biology, 79(5), 306-312. https://doi.org/10.1016/ j.mambio.2014.04.004

Springer, A. M. (1975). Observations on summer diet of roughlegged buzzards from Alaska. Condor, 77(3), 338-339. https://doi. org/10.2307/1366233

Sundell, J., Huitu, O., Henttonen, H., Kaikusalo, A., Korpimäki, E., Pietiäinen, H., ... Hanski, I. (2004). Large-scale spatial dynamics of vole populations in Finland revealed by the breeding success of vole-eating avian predators. Journal of Animal Ecology, 73(1), 167178. https://doi.org/10.1111/j.1365-2656.2004.00795.x

Tast, J., Kaikusalo, A., \& Lagerström, M. (2010). Breeding biology of rough-legged buzzards Buteo lagopus at Kilpisjärvi, NW Finnish Lapland, in relation to rodent cycles. Kilpisjärvi Notes, 22, 1-9.

Terraube, J., Villers, A., Ruffino, L., Iso-livari, L., Henttonen, H., Oksanen, T., \& Korpimäki, E. (2015). Coping with fast climate change in northern ecosystems: Mechanisms underlying the population-level response of a specialist avian predator. Ecography, 38(7), 690-699. https://doi.org/10.1111/ecog.01024

Therrien, J. F., Gauthier, G., Korpimäki, E., \& Bêty, J. (2014). Predation pressure by avian predators suggests summer limitation of smallmammal populations in the Canadian Arctic. Ecology, 95(1), 56-67. https://doi.org/10.1890/13-0458.1

Wiklund, C. G., Angerbjörn, A., Isakson, E., Kjellen, N., \& Tannerfeldt, M. (1999). Lemming predators on the Siberian tundra. Ambio, 28(3), 281-286.

Yee, T. W. (2015). Vector generalized linear and additive models: With an implementation in R. New York, NY: Springer.

\section{SUPPORTING INFORMATION}

Additional supporting information may be found online in the Supporting Information section at the end of the article.

How to cite this article: Fufachev IA, Ehrich D, Sokolova NA Sokolov VA, Sokolov AA. Flexibility in a changing arctic food web: Can rough-legged buzzards cope with changing small rodent communities? Glob Change Biol. 2019;25:3669-3679. https://doi.org/10.1111/gcb.14790 